\title{
Correction to: Promise and Peril of Big Finance
}

\section{Correction to:}

Chapter 3 in: G. Peterson et al., Navigating Big Finance and Big Technology for Global Change, Palgrave Studies in Impact Finance, https://doi.org/10.1007/978-3-030-40712-4_3

The original version of this chapter has been revised with some belated corrections. The chapter has been updated with the changes.

The updated version of this chapter can be found at https://doi.org/10.1007/978-3-030-40712-4_3 